\title{
Natural Born Transhumans
}

Naturalmente transhumanos

\author{
Karina SiLVIA Pedace $\left(\mathbb{D}^{a}\right.$ \\ TOMÁS BALMACEDA ${ }^{b}$ \\ DIEGO LAWLER ${ }^{\mathrm{C}}$ \\ DIANA I. PÉREZ ${ }^{d}$ \\ MAXIMILIANO ZELLER ${ }^{\mathrm{e}}$
}

\begin{abstract}
This work promotes the thesis that humans are naturally transhuman. In order to achieve this, we present in the first two sections some examples of technological devices assembled to human beings, and we critically review the assumptions and dichotomies on which the idea of human enhancement is based according to the ordinary transhumanist vision. Thirdly, we present the thesis of the Extended Mind to support our intuition. Fourthly, we dismantle the most relevant philosophical dichotomies that structure the transhumanist position. Finally, we recapitulate the reasons why we should wake up from the transhumanist dream.
\end{abstract}

a Universidad de Buenos Aires/Universidad Nacional de La Matanza (UBAIIF/SADAF/CONICET), Ciudad Autónoma de Buenos Aires, Argentina. PhD in Philosophy, e-mail: karinapedace@gmail.com

${ }^{\mathrm{b}}$ Universidad de Buenos Aires (UBA-IIF/ SADAF/ CONICET), Ciudad Autónoma de Buenos Aires, Argentina. PhD in Philosophy, e-mail: tomasbalmaceda@gmail.com

c Instituto de Investigaciones Filosóficas - Sociedad Argentina de Análisis Filosófico/CONICET, Ciudad Autónoma de Buenos Aires, Argentina. PhD in Philosophy, e-mail: diego.lawler@gmail.com

d Universidad de Buenos Aires (UBA-IIF/SADAF/CONICET), Ciudad Autónoma de Buenos Aires, Argentina. PhD in Philosophy, dperez@filo.uba.ar

e Universidad de Buenos Aires (UBA), Ciudad Autónoma de Buenos Aires, Argentina. Master in Philosophy, e-mail: facildeacordar@gmail.com 
Keywords: Transhumanism. Human Enhancement. Extended Mind. Prothesis. Artificial Intelligence.

\section{Resumo}

Este trabalho promove a tese de que os humanos são naturalmente transhumanos. Para isso, apresentamos nas duas primeiras seções alguns exemplos de dispositivos tecnológicos montados para seres humanos e revisamos criticamente as hipóteses $e$ dicotomias em que se baseia a ideia de aperfeiçoamento humano de acordo com a visão transhumanista tradicional. Na terceira seção, apresentamos a tese da mente estendida como suporte da nossa intuição. Na quarta seção, desmontamos as dicotomias filosóficas mais relevantes que estruturam a posição transhumanista e, finalmente, recapitulamos as razões que nos impulsionam a acordar do sonho transhumanista.

Palavras-chave: Transhumanismo. Aperfeiçoamento humano. Mente estendida. Prótese. Inteligência artificial.

\section{Introduction}

Transhumanism has been a hot topic in the last years. A lot has been written and discussed in the last decade about it and probably a lot more will be written and discussed in the next ten years. Evidence of the use of devices and the development of practices to improve and extend human capabilities dates back several centuries. The oldest known prosthesis is an iron and bronze leg replacement dating back to 300 BC; Pliny the Elder wrote about a Roman general in the Second Punic War who had his right arm amputated but had an iron hand placed on it to hold his shield and was able to return to the battlefield (GONZÁLEZ, 2005). Nevertheless, in recent years, advances in technology, digital computing, artificial intelligence as well as the creation of more durable, lightweight materials, boosted the idea that we may be facing an impending revolution that will profoundly change our human nature. For some, this is not just a dream, but a reality: the possibility of extending our capabilities and overcoming everlasting obstacles (HAUSKELLER, 2009). For others, however, it is a nightmare that threatens to consolidate inequities or even undermine the very foundations on which democracy rests (FUKUYAMA, 2004). 
In this paper we will deal with the transhumanist thesis characterized by the idea of human enhancement, making explicit the assumptions and dichotomies behind its formulation, in order to put into doubt its plausibility. We will only be concerned with the notion of "human enhancement" connected with developments generated by the use of artificial intelligence (AI). We will leave aside the improvements that have been carried out with genetic therapies, tissue bioengineering or regenerative treatments with nanotechnology (i.e. the line of biomedical improvements). There are two trends within the transhumanist thesis. First, those who associate transhumanism with the search for immortality (DIÉGUEZ, 2017). Second, those who link it with improvements in our physical and intellectual capacities, including capacities to perform actions naturally beyond our reach or to increase our cognitive capacities. We will only be concerned in this paper with the second trend. The paper is organized as follows. First, we will present some current examples of devices that allow "human enhancement" to be discussed throughout the work. Secondly, we will address the idea of human enhancement and the philosophical assumptions on which it is based. Thirdly, we will present the Extended Mind thesis to support the central proposal of this work: humans are naturally transhuman. Finally, to deepen this argument we will dismantle the questionable dichotomies that structure the transhumanist position.

\section{The transhumanist dream: some examples of technological advances}

A number of shocking advances with devices that use artificial intelligence have been done in the last years. This is a trend that is often referred to in the current scientific literature as 'cyborgization' and refers to the 'incorporation of devices, nanorobots and computers into the body". These practices are usually presented as novel. The line of reasoning is simple: humans have been for many centuries simply humans, but due to the technological advances of the twentieth and twenty-first century, we have managed to design objects that allow us to think that 
we will soon transcend our "human nature", and will generate a new type of beings in the world: transhuman beings.

There are some devices which help people to overcome human limitations in direct connection with the body - for example, in the case of people who suffered a physical damage - and other devices designed to improve our cognitive capacities such as memory, attention and calculation, among others. Some of the astonishing creations in the last years include the following.

(1) A prosthesis which benefits from current technological advances such as microprocessors, machine learning algorithms and electrically sensitive components of the neural connections. In April 2016, scientists at Battelle Memorial Institute in Columbus, Ohio, announced that a quadriplegic patient who had a chip implanted in his brain was able to control a robotic sleeve attached to his arm and hand. At first, the subject was able to perform coarse movements, but after a year of practicing he was able to use a spoon, and twelve months later was able to grab a glass from the table, slide a credit card through a slot and even enjoy playing a video game (BOUTON et al., 2016).

(2) In 2001, Jesse Sullivan lost both arms in an accident. Seven years later, he can move his prosthetic arms connected with his chest muscles. The interesting detail in this case is that his prosthetic arms allows him to get information about the temperature of what he touches (ROUSCHE et al., 2008). The advances are not only in the upper limbs. Zac Vawter, who lost a leg in a motorcycle accident in 2009, learned to control with his brain a prosthesis specially designed for him. The nerves of his amputated leg were "reconnected" to his hamstring muscles, from where he controls his orthopedic limb. A team led by scientist Levi Hargrove created a "muscle reinnervation" that allows Vawter's thigh electrodes to translate the neural signals that move the prosthesis. In order to show the virtues of his new leg, in 2012 Vawter climbed the 103-steps Willis Tower in Chicago, which until 1993 was the tallest building in the world, on his own. Although it was estimated that it would take an hour, he finally performed the feat in 45 minutes (HARGROVE et al., 2013).

(3) There are also other kinds of devices controlled with brain implants that do not need to be attached to someone's body. In the case of a quadriplegic patient, 
Cathy Hutchinson, for example, she can control a prosthesis thanks to a device called the BrainHGate, which bypasses the nerve circuits broken by the brainstem stroke and replaces them with wires that run outside Hutchinson's body (KWOK, 2013). The implanted sensor is the size of a small pill and translates the electrical stimuli in the patient's brain into a kind of robotic hand allowing her, for example, to drink a cup of coffee on her own. The interesting thing about this case is that the arm is not attached to Hutchinson's body, but separated from it, remaining in her immediate environment. Researchers suggest that she could even control it from hundreds of miles away but there are also reasons to believe that it could be much more: in an experiment conducted at Duke University in North Carolina, brain signals from a monkey were sent over the Internet to a robotic arm in Japan, crossing more than 11,000 kilometers (O’DOHERTY et al., 2011). This opens up the possibility for this type of enhancement extending the power of control over external objects in an unprecedented way.

(4) There are also devices designed to 'cyborgizate' our cognition by means of brain prostheses. The most popular case of cognitive enhancement is that of the English artist Neil Harbisson, who was born with acromatopsia, an anomaly in vision that prevents us from seeing colors other than black, white and shades of gray. At the age of 30, he designed Eyerborg, a sort of antenna placed in his head, connected to a chip in his brain that transforms the light waves it detects into sound frequencies that are perceived by Harbisson as musical notes (WARWICK, 2016). In this way, he can "hear" the colors around him including some that are invisible to the human eye (infrared and ultraviolet). Since his antenna is connected to the Internet, he can receive visual and auditory information directly into his brain from distant points on the planet. Its cyborg condition enables him to make artistic presentations and novel works of art and performances.

(5) There are also interfaces which directly connect brains with technological devices. The most promising approach is transcranial direct-current stimulation (tDCS): using electrodes placed on the head to run a mild electrical current through the brain. The first results of this technique show that tDCS, which is painless, can increase brain plasticity, making it easier for neurons to fire. Cognition is improved in this manner, allowing subjects to learn and remember more items, from new 
languages to mathematical operations (FISICARO et al., 2020). This kind of technology, which can stimulate with an electrical current precisely those parts of the brain that respond best to tDCS, could be the key to develop a complete brainmachine interface. There are many possibilities, but one of them is to provide full access to digital information stored on a hard disk or in the cloud, such as the Internet, making it possible to retrieve digital data instantly.

(6) The most provocative proposal, still at a test stage, is computer engineer Ray Kurzweil's dream. He is well known for having developed the first electronic reader for the blind, the voice recognition system that is at the base of current virtual assistants such as Siri or Alexa, as well as the first digital scanner, among other high-impact inventions. Kurzweil predicts that by the 2040s it will be possible to "upload" brains to the cloud "living in various virtual worlds and even avoiding aging and evading death" (VON NEUMANN; KURZWEIL, 2012).

\section{The idea of "human enhancement"}

If we consider the examples just presented, we note that the first four devices were made to restore lost capacities to human beings who have suffered a traumatic situation. In these cases we are faced with the idea of reparation; in the face of a biological deficiency, technology would allow us to restore our lost capacities. The assumption beneath this technological dream is that we are our biology. However, if we use these devices in humans who have not gone through such losses, people could improve and/or increase their natural capacities ${ }^{1}$. In the context of artificial intelligence, human enhancement is related to the coupling of designed devices with biological organisms seeking to improve their performance when accumulating, storing, processing, and meaningfully manipulating information.

Transhumanism considers that all human beings are biological entities ("we are our biology"), even if our biology is unfinished, incomplete and deficient. Some

\footnotetext{
${ }^{1}$ We leave here in parentheses the question of whether quantitative improvements could generate a qualitative leap towards "singularity" or a "post-human" condition (BOSTROM, 2005).
} 
philosophical anthropologists maintain that a human being is an essentially negative being, "organically helpless, without natural weapons, without organs of attack, defence or flight, with senses of efficacy not very significant" (GEHLEN, 1993, p. $63)^{2}$. If this is our natural condition, then it should be improved with artificially designed devices that allow us to "repair" the deficiencies with which Mother Nature created us.

The elaboration of the thesis of human enhancement, independently of how the notion of enhancement (ALEGRÍA, 2016) is interpreted, is supported by three affirmations, two of them coming from Philosophical Anthropology and the remaining one from Philosophy of Technology.

The first idea is that human beings, as biological organisms, are deficient, since their natural organic capabilities are imperfect, even unfitting for life ${ }^{3}$. According to the second claim, awareness of this incompleteness promotes a compensatory movement to overcome our biological weaknesses. Thus, if Nature failed and left the human being incomplete, at the same time Nature repaired that defect, giving us the conscience of that unfinished and fragile condition.

The claim from Philosophy of Technology holds that the devices and technological systems are prosthesis whose manufacture comes motivated by the conscience of the deficiency of our biological endowments. These prostheses and artifacts would compensate for the original and natural handicap of human beings; to illustrate this with a simple example, the absence of lint that exposes the human being to climate inclemency is compensated with the control of fire and the invention of clothing 4 .

The transhumanist idea of developing devices with artificial intelligence for human enhancement subscribes to the above affirmations and goes one step

\footnotetext{
${ }^{2}$ The myth of Epimetheus portrays the failed distribution of gifts that makes a human being unable to survive (STIEGLER, 1998).

${ }^{3}$ The thesis of human being as an incomplete animal was expressed by Arnold Gehlen (1993, p. 33) as follows: "Man, exposed like the animal to the wild nature, with his congenital physical and instinctual deficiency, would be in all circumstances unfit for life. But these deficiencies are compensated for by his ability to transform uneducated nature and any natural environment; however, it may be constituted in such a way that it becomes useful to his life".

${ }^{4}$ See Ortega y Gasset (1998, p. 36): "every technique has that wonderful quality of being a fabulous and great orthopedics".
} 
further: it promotes the possibility of an enhancement in the capabilities of the human biological organism beyond merely fixing our natural flaws. It would not only be a matter of compensating our deficits but also of increasing human capabilities without limits. In this sense, technological devices and systems would leave their condition of prosthesis and would be transformed into improvement artifices. Enhancement would imply quantitative increases that would go beyond mere compensation; it would be a matter of designing and producing technology to overcome the biological limits of the species (BOSTROM, 2005).

The Anthropological theses imply that human beings are "incomplete animals" aware of their biological incompleteness. The image promoted is that of a being restricted to its biology and defined as organically weak. On the other hand, the Philosophy of Technology thesis fits easily into this narrative by claiming that technological devices and systems, conceived and created by human beings, are better understood when they are considered as prostheses, namely "artificial structures that substitute, complete or enhance, partially or totally, a certain performance of the organism" (MALDONADO, 1998, p. 157) - constituting in this manner "the new world of technology (...) a gigantic orthopedic apparatus" (ORTEGA Y GASSET, 1998 p. 36).

In this view, human enhancement is at the origin of our initial condition; from the beginning we have imagined and built compensations and increased extensions of our capacities; we could not have done otherwise if we wished to survive. Thus, human enhancement has been there since we made the first tools. Human enhancement is the result of an unfinished biological body that is too endangered to survive in a hostile environment.

Those instruments, when they are treated as prostheses, are considered external to the unfinished biological body. Artifacts are produced, used, kept and transmitted from generation to generation, but they are not constitutive of the human condition; they are merely coupled with the biological body, being able to be uncoupled. Transhumanism is especially obsessed with the body and its avatars. The body is conceptualized as a biological machine, whose parts are becoming obsolete and need to be replaced, or whose functions, biological and/or cognitive, can be 
improved. The examples mentioned in the previous section portray some of the devices designed to be coupled with the body.

On the other hand, technology is pictured as an inventory of possibilities, which exist outside of these biological bodies and to which we can go back for improvement. Given its external condition, we maintain an instrumental relationship with this technological stock, tied to the maximization of our desires and/or interests. The technological devices and systems end up being mere mediators of our actions. In this sense, the devices are used by people but are not integrated to them. "Use" supposes that the human being represents the technological artifact, its characteristics, and calculates the benefits of assembling it to his body with the purpose of replacing or increasing functions. This view contrasts with the possibility of a real incorporation, where the artifacts completely reconfigure the organic body scheme as a consequence of the human person manipulation, exploitation and transformation that the human person carries out. From this alternative perspective, the artifacts themselves become part of the human person and its processes, and hence the agent is conceived independently of its biological limits. Nature becomes artificial and artificial devices become part of our nature.

In this paper we want to defend the thesis that we are not only our biology. There is not a human nature grounded exclusively on our biological, unconditioned and ahistorical constitution. On the contrary, human beings depend constitutively on technological artifacts and systems. In the following section we will see how the idea of the extended mind shows that the human condition was from the very beginning a transhuman condition, that is, a hybrid condition, historically reconfigured by organic, mental, social and cultural structures contingently assembled.

\section{The idea of the extended mind: We are naturally transhuman}

In 1998 Andy Clark and David Chalmers published the brief article "The Extended Mind", which had already been circulating in specialized media since 1995. Andy Clark also published three books (CLARK, 1997; 2003; 2011) in which 
he develops these seminal ideas in more detail, refining and defending them from various attacks from their individualist detractors. The central ideas of these works have been widely discussed over the past 20 years and certainly will still be the subject of debate in the future.

The presentation of the Extended Mind thesis in Clark and Chalmers' original text was centered on what they called the "parity principle," formulated in the following terms:

If, as we confront some task, a part of the world functions as a process which, were it done in the head, we would have no hesitation in recognizing as part of the cognitive process, then that part of the world is ... part of the cognitive process (CLARK; CHALMERS, 1998, p. 29).

This principle rests on the functionalist view of mind, according to which our cognition is a "program" that runs — at least in principle — on our gray matter. Traditionally functionalism rescued the individualistic manifest image of our mind/cognition. The prevalent idea in our culture is that we, human beings, think in isolation from our environment (we could still think locked up in a prison for years, or in a spaceship, or in a giant test tube like Neo in the "Matrix"). The same intuition lies behind some fictions about "body-switching" (a woman whose soul/mind is transported into a man's body; or from a child to an adult; or from one friend to another, etc.) Individualism finds one of his finest formulations in the work of Descartes, who, deceived by the evil genius, could conceive of himself "as without hands, without eyes, without flesh, without blood, as lacking all sense, but in the false belief of having all this" (DESCARTES, 1996, p. 15), that is to say, he emphatically maintained that the mind-body dualism rested on the idea of a Soul or Ego completely independent of all materiality.

However, there are reasons to put this image into question, and to advance an alternative one including material elements and the environment (both natural and the one designed by human beings) as essential parts of our cognition. If this alternative view is right, the Cartesian image is an incorrect conception of the world.

In fact, if we adopt an embodied vision of the human mind, the fictions mentioned above would be incomprehensible to us. We would acknowledge that the mind/soul of a woman transported to the body of a man would have a lot of work to do in adjusting her cognitive processes, her body image, and all her motor actions 
on the world; in addition, of course, to many even vital activities that men and women perform in a different way, given the behavioral patterns determined by the society in which they live and the biology their bodies. Note that these behavioral guidelines are already part of our daily body schemes and we do not think about them but follow them implicitly and automatically.

Something similar occurs if we adopt the extended mind hypothesis: when we travel, or if we move and start inhabiting a different environment from the usual one, we need to adjust our behavior to the new environment, i.e. the new bed, the new location of doors and walls in the house, etc. And of course, to the new technology we have, or to the lack of technology that is usual for us (as when we travel to some place where we lack the constant internet connection that we usually have). In a nutshell: the designed niche that surrounds us is a constitutive part of the cognitive process we undergo, that is why changing the environment changes our cognitive processes, and also our actions, our ways of making decisions, making plans, etc. It should be noted that although Clark embraces a functionalist point of view, he argues against individualism.

Let us examine some of the reasons that may induce us even today to adopt the individualistic illusion. There is a huge variety of different technologies and technical devices we are coupled to. We can make a distinction between opaque technologies and transparent ones (CLARK, 2003, chapter 2). We are always aware of some technological artifacts, even when we have the greatest mastery of them: nobody forgets that they are using a smartphone as a GPS when they navigate a city. However, there are many technological artifacts that — beyond the training period — become invisible to us since we adapt our body (including our brain, of course!) and our behavior in such a way that we become one with the artifact. Think, for example, of the glasses. Many times we are not aware that we have them on, to the point that sometimes we go to sleep with them or get into the shower without taking them off. Something similar happens with a hearing aid or with the famous example analyzed by Maurice Merleau-Ponty in the Phenomenology of Perception with the stick used by a blind person (BOSTROM, 2005). In all these cases, the task is performed by a human being coupled with an object designed by humans to improve the individual's abilities (visual, auditory, mobility, etc.). 
Hence, it is important to notice that there are design objects that reconfigure our cognitive and behavioral abilities and, when they become imperceptible to us, we forget that we are coupled to them. We live our human lives with this kind of artifacts from the cradle, and no one teaches how to use them (unlike others that require explicit teaching and many years of training to properly couple with them). Let's think of a contemporary toddler with a smartphone. From the moment she is born, she has had contact with these devices, she sees her parents using it, she grabs it, manipulates it, and quickly, without anyone teaching her, she knows how to touch the appropriate icon to play her favorite game, or watch videos. No one teaches her anything, she learns by imitation (like so many other things young children learn by imitation). It is common for parents to be surprised at this and think their child is very talented. Instead, the talent is in the team that developed that artifact. The key is in the intelligent design of the device. The smartphone's interface was designed so that anyone can use it without knowing anything. The design specifications are absolutely opaque to the user, but the use of the device is completely transparent.

Whether or not there is explicit instruction in the use of these design objects, their correct use requires training (which can be simply a trial and error mechanism, experience with similar devices, time of use or a more institutional training). Sometimes it requires a very brief training and sometimes many years (like a musician who need many years in order to become a virtuoso with an instrument like the violin). Note that in the examples we gave in the first section the proper use of the designed prosthesis requires years of training. This training involves two things. Firstly, it requires a set of social practices that allow the use of the objects in question to be transmitted from one person to another. A set of practices that include the rules for correct use: what can and cannot be done with the device in order to give it the use for which it was designed, and consequently to increase our cognitive abilities thanks to our effective coupling with it. Secondly, cultural transmission practices are also necessary to develop the skills needed in order to use some devices. Let us think once again of the different practices of music education, for example, that allow a child to learn playing an instrument. Or the training required by a neuroscientist in order to interpret an FMRI, or the image in an 
electronic microscope, or a medical surgeon which operates with a laser scalpel. It should also be noted that in the case of technologies whose use we learn without explicit training, they also imply a series of practices, at least of the first type, that is, cultural practices that are presupposed for in the correct use of the designed object. If a child takes a Smartphone and never uses it as such but as a block to build houses for her dolls, for example, we would not say that that child is correctly coupling herself with that device to perform the kind of cognitive tasks that users of that phone usually do.

It is also important to note that given the fact that the use of these design objects that enhance our cognitive abilities involves the acquisition of certain skills, the learning process may generate a substantive and definitive change in our brain wirings. Let us first think about prostheses, for example a prosthetic leg, a hearing aid, or the stick of a blind person. Without any doubt, the training we undergo in order to use these devices implies a certain reconfiguration of our brain, that enables us to walk with the orthopedic leg, or with the stick. This is more apparent in the cases mentioned in the first section in which brain chips are implanted in the subjects. Probably not all technological devices generate such substantial changes in our biological brain. If we know how to make addition, there will be no changes in our brain if we do it with a piece of paper and a pen, or with a calculator. However, we know that the brain of a skilled musician is different from the one of a layman (GASER; SCHLAUG, 2003). Thus, in some cases the coupling with artificial devices is sometimes ephemeral couplings, which do not alter our biology; however, there are others cases which require specific training that alter our biological constitution. In these cases we are coupled more permanently with them (although not necessarily all the time, the blind man does not sleep with his stick, nor does the musician do everything with his instrument; nonetheless, in both cases, many hours a day the individual is coupled to an artifact).

In addition to the fact that there are different types of technologies with which we couple, and different types of training and adaptive changes in our biology to carry out these couplings, there are different types of couplings. Some of them allow us to alternate between a purely internal realization of the cognitive task and a 
realization of the same task with a body-technology coupling; but there are some cognitive tasks that can only be realized with a coupling with external objects.

We all know that there are sums of too many figures that we cannot perform without resorting to a paper and a pencil or to a calculator. What would we say about the vehicle in which the addition is realized? Surely, we would have to admit that the same cognitive task (addition) is sometimes performed completely in the head (for example when adding $2+2$ or, in general, with small numbers). Sometimes it is optional, since we can perform certain sums in our head or on paper. Other times it is impossible for any human to perform the task "in the head", when we have to add very large figures that exceed the capacity of our working memory.

However, there are cognitive tasks that can only be performed by coupling us with an external object, because there is no way to perform that cognitive task "in the head". We think about writing a novel. Nobody can create a novel in his head and only then write it uninterruptedly and without corrections on a piece of paper. It is in the coupling between our creative mind and the materiality of what we are writing that the novel emerges (the same could be said of music and painting: the myth of the creative genius who has the entire symphony in his head is just that, a myth). The same thing happens with scientific creation. In his book Supersizing the Mind (CLARK, 2011), Clark begins with an anecdote from the Nobel Prize winner in Physics, Richard Feynman, who showed his original notes to a historian, Weiner, by stating:

"I actually did the work on the paper,". "Well," Weiner said, "the work was done in your head, but the record of it is still here." "No, it's not a record, not really. It's working. You have to work on paper and this is the paper. Okay?"

Mathematics and logic would not have advanced either, without an appropriate symbolic language that can be written on papers and blackboards in order to think about logical and mathematical problems.

The thesis that we defend in this work is, then, that a great part of our cognition is possible thanks to our constant and imperceptible coupling with physical objects designed by us for diverse purposes; artifacts we learn to use by virtue of a training which, many times, reconfigures our biological endowment. In some cases, it generates new cognitive capacities, and in others increases the already 
existing ones. We have a distorted image of the role played in our cognition by our brain as well as by the physical objects designed by us. The role of the brain is much less central than we think, the role of our artifactual niche is much greater than we assume. And culture is undoubtedly present in all our cognitive activities: through the designed objects with which we engage, through the brain reconfigurations produced by training.

We will now make explicit some of the central dichotomies that are behind the Cartesian image and induces us to have a transhumanist dream.

\section{Dismantling dichotomies}

In the first section of this paper we presented a series of examples in which some dichotomies impregnate the traditional philosophical vision as well as the manifest image of the world. Before analyzing them, it is necessary to clarify what a dichotomy consists of.

A dichotomy is not a mere distinction but entails the exhaustive and exclusive character of two categories that are presented as opposed and incompatible. For example, it is traditionally assumed that facts and values are mutually exclusive and incompatible dimensions of reality. It has been considered, for example, that facts are objective and values are subjective and that there is no possible encounter between them. Or that we can make an evaluatively neutral description of the facts involving no clue about how we value them. In other words, judgments of fact and judgments of value are irreconcilable and respond to alternative ways of approaching the world. However, Putnam has argued that if we consider certain types of ethical (thick) judgments we will notice that there is no way to separate between the facts and the values as the proponents of this dichotomy intended (especially logical positivists) (PUTNAM, 2002). Description and evaluation are inseparably interwoven.

In a parallel way, we will show in this section that in the cases considered in the first section regarding human improvement via AI, there are distinctions that were traditionally mistakenly conceived as dichotomous. We will argue that such a 
dichotomous understanding is not viable, given the interweaving of the notions of mind-and-body, individual-and-environment, internal-and-external, biology-andtechnology and biology-and-culture. If this is so, we are not merely biological beings isolated from the environment (material and cultural), whose materiality is merely accidental, and whose capacities are determined exclusively by our biology.

(1) Consider the case of the quadriplegic patient who had a chip implanted in his brain to control a robotic sleeve attached to his arm and hand with which he can drink a glass of water, or play video games. We might naively think that this case shows that our mind/brain functions as it does independently of our body, since we can move a robotic arm instead of the organic arm. In this sense an organic/biological arm or a mechanical arm are equally objects moved by the will of the subject, distinguishing strictly the material/contingent realm vs. the mental/will of the subject which would remain the same and operate in the same way no matter what "object" it moved. However, if we take into account our arguments in the last section, this dichotomous image of mind and body is wrong. The robotic arm is not a device that contingently attaches to the subject as he was before the accident. In fact the individual can only operate his robotic arm after many years of training. This training shows us that in most everyday actions whether with our organic arm or with a robotic arm, mind and body are interwoven. My (organic) body is not just a physical object driven by my mind (Cf. Merleau-Ponty, 1975, who uses concepts like those of the lived or own body and of lived space in order to emphasize the entanglement that exists between subject and world).

(2) Let us remember Jesse Sullivan who has prosthetic arms that respond to brain stimuli with which he moves his chest muscles allowing him to receive information about the temperature of what he touches. In this case we can see that not only the "psychological mind" but also the "phenomenal mind" (CHALMERS, 1996) are assembled with the bodily actions of the individual coupled with his artificial arms, showing that the mind-body dichotomy is not sustained in the phenomenological field either.

(3) The case of the quadriplegic patient Cathy Hutchinson is interesting because the prosthetic arm she drives with a chip implanted in her brain is not in her body but separate from it, in her immediate environment. This phenomenon 
presents us with a dilemma: either the arm is a constituent part of Cathy, when she performs certain actions - for example, when she takes a glass of water with her robotic hand - or Cathy simply ends up where her biological body ends, and the artificial arm is contingently/causally connected to her in performing the task. Note that the same dilemma occurs when we add up on a sheet of paper, noting the figures in columns. If the conception of the extended mind developed in the previous section is convincing, we could think that in this case we should lean towards the first horn of the dilemma and dilute the supposed dichotomy between an internal dimension, proper to the individual (biological) and an external dimension, proper to the environment, where the artificial arm is located.

(4) The artist Neil Harbisson states that he can hear colors. We have no doubt that the possibility of correlating sounds with colors, and of doing so automatically, must have required a period of learning/training, like when children learn colors ("learning colors" means, in fact, learning to discriminate them, i.e. correlating them with linguistic labels). This fact alone illustrates the presence of a cultural factor that blurs the transhumanist claim that there is a sharp divide between biology and culture. In other words, the training required involves immersion in community practices of categorization that challenge the idea that perception is a purely biological phenomenon. In Harbisson's case, he has to learn how to correlate the English labels for colors with the sounds he hear.

(5) The case of having our brain directly connected with digital information stored on a hard disk or in the cloud, such as the Internet, making it possible to recover data instantly, exemplifies the persistence of the internal/external dichotomy, although with a novel nuance compared to Cathy's case. In this fifth case, the supposedly external ingredient is informational in nature. Nevertheless, we can ask ourselves — as Clark and Chalmers (1998) do with regard to Otto's notebook - to what extent our constant coupling with external devices that store information is not constitutive of the cognitive process carried out instead of mere external elements of the environment contingently connected with the individual. Again, if the thesis of the extended mind is plausible, there are compelling reasons to challenge the individual/internal-environment/external dichotomy. 
(6) The example introduced by Kurzweil, finally, makes explicit the commitment to the residue of Cartesian dualism present in the transhumanist thesis. The idea of uploading (and later downloading) our brain to the Internet is only viable if we conceive our biological brain as the mere hardware of a computer program that constitute our mind/brain, that could run on a different physical stuff. The Cartesian presupposition present in this naive functionalist version of the mind would consist of considering that the program/software/mind is detachable from the material/hardware/biological substrate that implements it.

If we reject the dichotomous character of the distinctions mentioned (mind/body, internal/external, individual/environment, biology/culture, biology/technology), we can see ourselves as what we are: human animals, embodied minds, biological organisms coupled to objects created by us, biological organisms situated in cultural niches and involved in normative practices. In other words: we are not our mere biology and we should wake up from the transhumanist “dream", built on an unacceptable picture of our human nature.

\section{Conclusions}

In this paper we have argued in favor of the intuition that human beings are naturally transhuman. And they have been since the beginning of their existence on this planet. If we are not philosophically attentive, the most recent examples of human enhancement through technological systems of artificial intelligence can lead us to have a distorted image of what is really happening.

The transhumanism that promotes human enhancement is based on assumptions that promote an erroneous image of a human being, as well as a poor understanding of technology and the relationships we have with it. In this article we have appealed to the Extended Mind thesis to point out important reasons that invite us to dismantle the Cartesian illusion that prevents us from understanding cognition as a human process that is carried out by our constant and imperceptible coupling with physical objects — which are designed by us for multiple and diverse purposes. We are trained to deal with these artifacts in our daily practices. Our 
biology is reconfigured because coupling with these technological systems reconfigures our biology. Moreover, this has been the case since the beginning of our life as a species.

The understanding of the Extended Mind thesis promoted in this article dismantles the transhumanist dream of a new human being - a product of the enhancement of her capacities. This is a dream fed by dichotomies (mind/body, internal/external, individual/environment, biology/culture, biology/technology) that still permeate our culture. Identifying and analyzing them is the first step to putting them to rest. Once deactivated, we will be able to perceive clearly that there is a sense in which there is no human enhancement at all as transhumanism understands it; the reason is simple: we have never been merely a biological body.

\section{References}

ALEGRÍA, J. P. Transhumanismo: hacia un nuevo cuerpo. Daimon Revista Internacional de Filosofia, p. 489-495, 2016.

BOSTROM, N. A history of transhumanist thought. Journal of evolution and technology, v. 14, n. 1, apr. 2005.

BOUTON, C. E., et al. Restoring cortical control of functional movement in a human with quadriplegia. Nature, v. 533, n. 7602, p. 247-250, 2016.

CHALMERS, D. J. The conscious mind: In search of a fundamental theory. Oxford: Oxford University Press, 1996.

CLARK, A. Being there: Putting brain, body, and world together again. Cambridge: MIT Press, 1997.

CLARK, A. Natural-Born Cyborgs: Minds, Technology and the Future of Human Intelligence. Cambridge: MIT Press, 2003.

CLARK, A. Supersizing the Mind: Embodiment, Action and Cognitive Extension. Cambridge: MIT Press, 2011.

CLARK, A.; CHALMERS, D. The extended mind. Analysis, v. 58, n. 1, p. 7-19, 1998.

DESCARTES, R. Meditations on First Philosophy. Cambridge: Cambridge University Press, 1996.

DIÉGUEZ, Antonio. Transhumanismo: La búsqueda tecnológica del mejoramiento bumano. Barcelona: Herder Editorial, 2017. 
FISICARO, F. et al. "Self-Neuroenhancement": The Last Frontier of Noninvasive Brain Stimulation? Journal of Clinical Neurology, v. 16, n. 1, p. 158-159, 2020.

FUKUYAMA, F. Transhumanism. Foreign Policy, n. 144, p. 42-43, 2004.

GASER, C.; SCHLAUG, G. Brain structures differ between musicians and non-musicians. Journal of Neuroscience, v. 23, n. 27, p. 9240-9245, 2003.

GEHLEN, A. Antropología filosófica: Del encuentro y descubrimiento del hombre por sí mismo. Barcelona: Paidós, 1993.

GONZÁLEZ, J. M. D. et al. Robótica y prótesis inteligentes. Revista Digital Universitaria, v. 6, n. 1, 2005.

HARGROVE, L. J. et al. Robotic leg control with EMG decoding in an amputee with nerve transfers. New England Journal of Medicine, v. 369, n. 13, p. 1237-1242, 2013.

HAUSKELLER, M. Prometheus unbound: transhumanist arguments from (human) nature. Ethical Perspectives, v. 16, n. 1, p. 3-20, 2009.

KWOK, R. Once more, with feeling. Nature, v. 497, n. 7448, p. 176, 2013.

MALDONADO, T. Crítica de la rąón informática. Barcelona: Paidós, 1998.

MERLEAU-PONTY, M. Fenomenología de la percepción. Barcelona: Península, 1975.

O'DOHERTY, J. E. et al. Active tactile exploration using a brain-machine-brain interface. Nature, v. 479, n. 7372, p. 228-231, 2011.

ORTEGA Y GASSET, J. Meditación de la técnica y otros ensayos sobre ciencia y filosofía. Madrid: Alianza Editorial, 1998.

PUTNAM, H. The collapse of the fact/value dichotomy and other essays. Harvard: Harvard University Press, 2002.

ROUSCHE, P. et al. Translational neural engineering: multiple perspectives on bringing benchtop research into the clinical domain. Journal of neural engineering, v. 5, n. 1, p. P16, 2008.

STIEGLER, B. Technics and time: The fault of Epimetheus. Stanford: Stanford University Press, 1998.

VON NEUMANN, J.; KURZWEIL, R. The computer and the brain. Connecticut: Yale University Press, 2012.

WARWICK, K. Transhumanism: some practical possibilities. FIfF-Kommunikation. Zeitschrift für Informatik. und Gesellschaft, v. 2, p. 24-25, 2016. 